\title{
NARRATIVAS DOCENTES DE EDUCAÇÃO SEXUAL EM PERSPECTIVAS GERACIONAIS
}

\author{
TEACHING NARRATIVES ABOUT SEX EDUCATION IN \\ GENERATIONAL PERSPECTIVES
}

\author{
NARRATIVAS DE ENSEÑANZA DE EDUCACIÓN SEXUAL \\ EN PERSPECTIVAS GENERACIONALES
}

\author{
Luisa Machado ${ }^{1}$; Nathany Pacheco Sousa ${ }^{2}$; Sandra Lucia Escovedo Selles ${ }^{3}$
}

\begin{abstract}
Resumo: Neste artigo, examinamos mudanças de enfoque de educação sexual que foram sendo engendradas em práticas docentes. Examinamos essas mudanças em narrativas orais de oito professores/as de Ciências e Biologia de quatro gerações definidas pelo início das suas atividades profissionais (1980-2010). A análise das narrativas foi realizada em diálogo com contribuições dos estudos do currículo, dos saberes docentes e das finalidades educacionais. As práticas de educação sexual relatadas integram os saberes experienciais dos/as docentes em contextos sociais e pedagógicos atravessados pela mescla de finalidades educacionais e condicionantes temporais. As narrativas sugerem possibilidades de trabalhar a educação sexual, sensíveis aos riscos que a população estudantil corre em função da violência sexual e dos preconceitos de gênero que a exclui socialmente.
\end{abstract}

Palavras-chave: Educação Sexual; Narrativas de professores/as de Ciências e Biologia; Gerações Docentes; Saberes docentes; Finalidades Educacionais.

\begin{abstract}
In this article, changes in the focus of sex education have been examined related to teaching practices. These changes have been researched by the use of narratives of eight science and biology teachers from four generations, which have been defined by the beginning of their professional activities (1980-2010). The analysis was carried out in dialogue with contributions from curriculum studies, teaching knowledge and educational purposes. The sexual education practices show teachers' experiential knowledge in social and pedagogical contexts crossed by the integration of educational purposes and temporal constraints. The narratives suggest possibilities of working with sex education, in tune to the risks that the student population runs due to sexual violence, gender prejudices and cultural definitions that exclude it socially.
\end{abstract}

Keywords: Sex education; Narratives of Science and Biology Teachers; Teaching Generations; Teaching Knowledge; Educational Purposes.

\footnotetext{
${ }^{1}$ Mestranda em Educação - Universidade Federal Fluminense (UFF), Niterói, RJ - Brasil. Professora da Rede Municipal de Teresópolis. E-mail: luisaatl@hotmail.com

${ }^{2}$ Bacharel em Ciências Biológicas - Universidade Federal Fluminense (UFF). Niterói, RJ - Brasil. Bolsista PIBICV/CNPq (UFF). E-mail: nathanypacheco@id.uff.br

${ }^{3}$ Doutora em Educação em Ciências - University of East Anglia, Inglaterra. Professora Titular - Faculdade de Educação - Universidade Federal Fluminense (UFF). Niterói, RJ - Brasil. E-mail: escovedoselles@gmail.com
} 
DOI: http://doi.org/10.46667/renbio.v14i1.535

Resumen: En este artículo, examinamos los cambios en el enfoque de la educación sexual que se han generado en las prácticas docentes. Examinamos estos cambios en las narrativas orales de ocho profesores de ciencias y biología de cuatro generaciones definidas por el início de sus actividades profesionales (1980-2010). El análisis se realizó en diálogo con aportes de estudios curriculares, conocimientos docentes y propósitos educativos. Las prácticas de educación sexual reportadas integran el conocimiento experiencial de los docentes en contextos sociales y pedagógicos atravesados por la mezcla de propósitos educativos y condiciones temporales. Las narrativas sugieren posibilidades de educación sexual, sensibles a los riesgos que sufren la población estudiantil por la violencia sexual, los prejuicios de género y las definiciones culturales que la excluyen socialmente.

Palabras clave: Educación sexual; Narrativas Profesores de Ciencias y Biología; Generaciones de Profesores; Conocimientos Docentes; Propósitos educativos.

\section{Introdução}

Nos últimos anos, o Brasil tem assistido o avanço do que vem sendo considerado um novo conservadorismo (LACERDA, 2019), o qual coloca em xeque direitos humanos, conquistas sociais, reconhecimento da diferença, dentre outros abusos de ordem social e cultural, o que vem enfraquecendo práticas democráticas duramente conquistadas. Sem incorrer em exagero, uma parte substancial dos ataques desse novo conservadorismo tem se voltado para as atividades escolares e, em particular, exercido vigilância sobre a atividade profissional docente. As relações dos/as professores/as com suas turmas passaram a ser patrulhadas por grupos conservadores que, pormenorizadamente, instruem os estudantes para que tomem medidas legais e criminalizem a docência quando esta for julgada em oposição a ditos valores morais e religiosos de suas famílias. Direcionando práticas belicosas contra a docência, um alvo privilegiado tem sido o ensino de Ciências e Biologia e, assim, incidido sobre temáticas tradicionalmente consolidadas em suas histórias curriculares, principalmente, a teoria evolutiva, as temáticas raciais, de gênero e de educação sexual.

Dentro do acirramento do novo quadro conservador, a pertinência da educação sexual escolar vem sendo questionada porque estaria comprometida com tendências partidárias de esquerda, induziria à promiscuidade, ao sexo sem compromisso e exporia crianças e jovens a desvios morais conflitantes com as orientações de seus pais, o que comprometeria a instituição familiar. Seguindo em paralelo a esse quadro, os anúncios de violência sexual continuam ganhando as manchetes e mídias, revelando que o espaço preferencial onde tais abusos acontecem é esse mesmo ambiente familiar sacralizado pelos conservadores, no qual crianças e jovens compartilham o cotidiano com seus agressores ${ }^{4}$. Isso acrescenta um dado de realidade ao debate que, por um lado, expõe a incoerência dos argumentos contrários à educação sexual e, por outro, reacende a sua urgência como parte do currículo escolar, inclusive para alertar os estudantes das ameaças de abuso sexual.

Com efeito, no ensino de Ciências e Biologia, a educação sexual é um exemplo dessas temáticas que se situam na interface entre a biologia e as questões humanas, políticas, culturais

\footnotetext{
${ }^{4}$ Disponível em: Três crianças ou adolescentes são abusadas sexualmente no Brasil a cada hora . Acesso em: 19 fev. de 2021.
} 
DOI: http://doi.org/10.46667/renbio.v14i1.535

e sociais e se dirige especialmente às particularidades do público estudantil. Em um texto bastante divulgado, Paulo Freire (1998, p.41) afirma que o/a professor/a de Biologia não pode desconsiderar que as temáticas que ensina estão articuladas a essas questões. Alguns autores se aproximam desta proposição, como Simonneaux e Simonneaux (2012), para defenderem a inclusão de questões socialmente agudas (QSA): perguntas abertas no contexto de problemas não estruturados que integram o conhecimento na área das Ciências Humanas. Ou como preferem Gil e Eugênio (2018), "temas sensíveis": temáticas tratadas no ambiente escolar que implicam no confronto de valores e interesses e podem provocar constrangimentos nas tomadas de decisão. Ou, ainda, "conteúdos cordiais", como assumem Teixeira, Oliveira e Queiróz (2019), na defesa da educação orientada por direitos humanos. Com alguma semelhança, Moreira e Candau (2007) defendem a ideia de que os currículos sejam um espaço em que se explicita a ancoragem social dos conteúdos, para que seja evidenciada sua construção social, suas raízes históricas e culturais, pois, ao serem omitidas, tendem a ser tratadas como indiscutíveis, neutras ou atemporais. No ensino de Biologia, essas temáticas expõem fronteiras curriculares, pois não têm o conhecimento biológico stricto sensu como única referência.

De modo aproximado, Moreira e Candau (2007) defendem a ideia de que os currículos sejam um espaço em que se explicita a ancoragem social dos conteúdos, para que se evidencie sua construção social, suas raízes históricas e culturais, pois, ao serem omitidas, tendem a ser tratadas como indiscutíveis, neutras ou atemporais. No ensino de Biologia, essas temáticas expõem fronteiras curriculares, já que não têm o conhecimento biológico stricto sensu como única referência.

Considerada uma questão socialmente viva ou uma das temáticas sensíveis, a educação sexual, ao longo de sua história tem estado presente nas disciplinas Ciências e Biologia, ainda que permanecido no cerne de debates curriculares, ressignificada pelas dinâmicas sociais de seus tempos. Trata-se de uma temática de natureza complexa e multidisciplinar, disputada por finalidades educacionais que tanto a vinculam a informações biológicas quanto a inserem em processos subjetivos que demandam decisões sobre a vivência da sexualidade. Não por outra razão, essas discussões são cercadas por muitas divergências e vêm ganhando destaque em praticamente todas as sociedades ocidentais desde o século passado, abrangendo não somente as instituições familiares e religiosas, mas também as escolares. Cabe destacar que, no nosso país, essa temática já integra o currículo escolar desde o início do século XX e vem sendo defendida sob diferentes perspectivas pedagógicas ao longo de sua história (CÉSAR, 2009). Pode-se dizer que sua presença constituiu uma tradição no currículo de Ciências e Biologia.

Neste texto, elegemos a educação sexual como uma temática sensível que vem atravessando os espaços e os tempos escolares, provocando gerações de docentes a abordá-la no interior de suas aulas. Ao entender que as gerações docentes se sucedem em projetos não lineares de vida e de profissão, consideramos pertinente examinar algumas de suas práticas, ouvindo suas narrativas de como construíram suas próprias versões para o ensino dessa temática. Isso porque os/as professores/as não são meros transmissores de conhecimentos e saberes externos às suas próprias experiências de vida e às relações pedagógicas que 
DOI: http://doi.org/10.46667/renbio.v14i1.535

estabelecem com os estudantes; suas histórias de vida sustentam, em boa medida, suas escolhas e o modo como conduzem suas práticas.

Adicionar o componente geracional pode permitir que entendamos as soluções e invenções dos/as docentes para responder aos desafios da educação sexual e encontrar traços comuns de determinados contextos vivenciados por docentes de uma geração que, entretanto, produzem sentidos distintos em outra. Assim, o caráter relacional é um componente relevante para pensar como as gerações compartilham experiências comuns, ao mesmo tempo em que os sujeitos vivem suas experiências de modo particular.

Tomando esses e outros questionamentos, o artigo apresenta os resultados de uma pesquisa que tem como objetivo refletir sobre práticas de educação sexual desenvolvidas por docentes de Ciências e Biologia em coortes geracionais ${ }^{5}$ que cobrem o período de 30 anos. $\mathrm{O}$ artigo busca compreender essas práticas nas relações com os contextos educacionais e sociais brasileiros que atravessaram essas gerações.

\section{Educação sexual no Brasil: travessias de sua história}

Em diversos países, a história da educação sexual acompanha a organização da escolaridade, ora refletindo as necessidades sociais, ora induzindo e reprimindo, em termos biológicos e culturais, as representações de corpo. No Brasil, seguindo um caminho repressivo sobre os corpos desde o estabelecimento das escolas jesuíticas na Colônia, passando pelo Império e ingressando na República, no século XX a educação sexual exibe, na maior parte deste tempo, uma associação entre valores religiosos e moralizantes sobre as práticas sexuais, "uma visão cristã de condenação ao prazer sexual" (FONTOURA, 2018, p. 684). Configurouse, dessa maneira, uma estratégia de controle sobre a população, exercida principalmente nas instituições escolares. No início do século passado, o interesse sobre o estudo do sexo e da sexualidade foi liderado pela ciência médica que, unida a justificativas psicológicas e pedagógicas, também serviu a um projeto de nação republicana comprometida com ideias de branqueamento e de melhoramento da raça.

Assim, as propostas iniciais de educação sexual se confundem com ideologias racistas que pretendiam fixar um sentido de brasilidade. Como afirma Oliveira (2012, p.507), tratavase de uma "certa obsessão de certas camadas da intelectualidade brasileira" para resolver a "viabilidade da nação brasileira, posta em questão" desde o século anterior, diante do quantitativo de uma população herdeira dos abusos escravocratas. Pode-se, assim, entender que a "educação sexual", conforme se cunhou mais tarde, se confunde com as exigências de produzir uma identidade brasileira a partir de uma população miscigenada, um incômodo percebido como obstáculo para a nação partilhar valores civilizatórios exigidos pelas relações

\footnotetext{
5 "Grupos de pessoas nascidas em momentos próximos e que atravessam estágios sucessivos ao mesmo tempo." (COSTA JUNIOR; COUTO, 2015p. 1301).
} 
DOI: http://doi.org/10.46667/renbio.v14i1.535

internacionais. Em sua história, a educação sexual se constituiu, portanto, de forma inseparável de valores higienistas e eugênicos, defendidos tanto por cientistas quanto por educadores que partilhavam dessas ideias, como Fernando Azevedo, para quem, em 1922, essa defesa seria justificável devido ao "interesse moral e higiênico do indivíduo" e do "interesse da raça" (MARQUES, 1994 apud OLIVEIRA, 2012, p.507).

Orientado por enfoques higienistas e eugênicos, o debate acerca do ensino da sexualidade se institucionaliza e se intensifica nas primeiras décadas do século XX, carregado de visões religiosas que condenavam as manifestações corporais vistas como libidinosas em festas populares, como o Carnaval, e em outras manifestações associadas aos corpos negros. Essa institucionalização da educação sexual, ou o que Oliveira (2012, p. 508) reconhece como "os primeiros esboços de um programa de educação sexual no Brasil", foi protagonizada pelo Círculo Brasileiro de Educação Sexual (CBES), fundado em 1933 (FELÍCIO, 2012; OLIVEIRA, 2012; FONTOURA, 2018). Por duas décadas essa entidade foi responsável pela publicação de livros, pelo oferecimento de palestras e pela organização de eventos científicos e pela criação e publicação do Boletim de Educação Sexual, periódico com artigos dos mais eminentes sexólogos da época (CÉSAR, 2009). O fundador do CBES, José Albuquerque, identifica o sexo como "cativeiro moral" do povo brasileiro (OLIVEIRA, 2012, p. 514) a ser libertado pelo tratamento médico e educacional, definindo seus objetivos "a um projeto nacionalista civilizatório científico" (FELÍCIO, 2011, p. 5). A visão cristã de condenação ao prazer sexual disfarça-se em discurso científico (FONTOURA, 2018, p. 684), referendado pela indução ao racismo protagonizado pela Biologia.

A institucionalização dos saberes sexuais entre as cinco primeiras décadas do século passado contribuiu para a implementação da educação sexual nas escolas, especialmente no ensino de Ciências; entretanto, permaneciam restritos ao combate a doenças chamadas de venéreas e "vinculada aos esforços curriculares da escola para aperfeiçoar a linhagem racial branca", abordando a reprodução como função biológica do sexo (BRITZMAN, 2000). Fixouse, assim, um sentido de educação sexual racializado e como matéria de interesse médico e cristão. Desde então, a biologização e a patologização do sexo tornaram-se perspectivas hegemônicas nos programas e nas orientações curriculares, abrigadas em uma noção de neutralidade científica compatível com valores sociais moralizantes (KOHEN; MEINARDI, 2015).

Se tal sentido persiste desde o período varguista, a partir de 1960 houve uma tentativa de renovação em relação à prática pedagógica da educação sexual no Brasil. O mundo vivia nessa década uma revolução sexual sem precedentes, tendo o movimento Hippie e a pílula anticoncepcional como expressões dessas mudanças (RIBEIRO; MONTEIRO, 2019). Nesse período, que pode ser considerado a segunda onda da educação sexual brasileira, escolas de São Paulo, Rio de Janeiro e Belo Horizonte organizaram programas de educação sexual em conexão com as "novidades pedagógicas" e curriculares (AQUINO, 2012). Essas tentativas de renovação, contudo, foram de curta duração, pois, a partir de 1968 houve o aumento da censura e da repressão às liberdades individuais subsequente ao Golpe de Estado de 1964. 
DOI: http://doi.org/10.46667/renbio.v14i1.535

Com a ditadura, impôs-se um regime de controle e moralização dos costumes, especialmente, decorrente da aliança dos militares com setores da sociedade civil e o majoritário grupo conservador da Igreja Católica que os sustentavam. A educação sexual foi definitivamente banida de qualquer discussão pedagógica por parte do Estado e toda e qualquer iniciativa escolar foi suprimida com rigor (CÉSAR, 2009). Embora a estagnação provocada pelo regime militar seja destacada, Ribeiro e Monteiro (2019, p. 1255) entendem que não houve "uma proibição total e abrangente de se falar de sexo". Para os autores houve certa dose de permissividade expressa "em atitudes e comportamentos sexuais, o cinema e as instituições científicas deram o respaldo e o estímulo necessários para que a sociedade brasileira continuasse respirando os ventos da liberdade sexual, ainda que com algumas amarras e restrições". Nos anos 1970, tais ventos incluíram a proliferação das pornochanchadas, com exposição do nu, a divulgação de revistas à semelhança da revista estadunidense Playboy e, especialmente, a publicação da coleção "Amar: a realidade sobre a vida sexual", vendida em fascículos nas bancas de jornal (RIBEIRO; MONTEIRO, 2019, p.1256).

Após o fim do regime ditatorial, o processo de redemocratização rechaçava a censura e prezava a liberdade de expressão, incluindo nela as referências à sexualidade. Especialmente, em meados dos anos 1980, a demanda por trabalhos na área da sexualidade nas escolas aumentou, em parte também devido à preocupação dos educadores com o grande crescimento da gravidez entre os adolescentes e o risco da contaminação por HIV (vírus da Aids) entre os/as jovens. Embora com certa resistência à abordagem dessas questões no âmbito escolar, o temor da contaminação sexual parece ter favorecido a inclusão de temáticas de comportamento sexual nas aulas de Ciências e Biologia.

Nota-se que a educação sexual permaneceu sendo tratada sob concepções biomédicas e higienistas e o ensino do corpo humano priorizou o enfoque biologizado. Contudo, mudanças passaram a ser registradas, especialmente a partir dos anos 1990, quando normas e padrões culturais ligados à sexualidade, motivados pelos estudos de gênero e pelo acolhimento às diferenças, passaram a ser introduzidos. Com o crescimento dos movimentos feminista e LGBTI $+{ }^{6}$ no Brasil, surgem políticas públicas visando a compreender a sexualidade de forma integrada, sob perspectivas culturais, sociais, históricas e biológicas. Ribeiro e Monteiro (2019, p. 1257) destacam a indução dessas políticas públicas, pois "as ações governamentais efetivas incentivam o desenvolvimento de projetos e programas voltados para a igualdade entre homens e mulheres, o respeito à diversidade e o combate à homofobia".

A homologação dos Parâmetros Curriculares Nacionais, a partir da Lei de Diretrizes e Bases da Educação Nacional de 1996, e a introdução de "Orientação Sexual” como Tema Transversal nesta proposta de currículo escolar para o ensino fundamental sinalizam o

\footnotetext{
${ }^{6}$ Dentre a diversidade de siglas utilizadas para se referir à população de gays, lésbicas, bissexuais, travestis, transsexuais, intersexuais, entre outras identidades de gênero e orientações sexuais, optamos por utilizar a sigla LGBTI+ em acordo com o Manual de Comunicação LGBTI+ (REIS, 2018).
} 
DOI: http://doi.org/10.46667/renbio.v14i1.535

reconhecimento do papel da educação sexual nas escolas em perspectivas mais integradoras do que as pretensões biologizadas e patologizadas de anos anteriores. Embora seja considerado uma iniciativa progressista, Ribeiro (2009) entende que praticamente nada foi feito no sentido de formar professores/as capazes de trabalhar questões de sexo e sexualidade na escola. As razões para esse aparente fracasso, entretanto, fogem ao escopo deste artigo, sobretudo quando se reconhecem alterações significativas nesse período, como sugerem Ribeiro e Monteiro (2019) ao dar destaque, por exemplo, à criação do primeiro curso de Educação Sexual do país em 2012, na UNESP-Araraquara. Certamente, arbitrar sobre avanços nessa temática exige questionar a linearidade histórica e enfrentar desafios em seus respectivos tempos.

Como a história é dinâmica e desafia as análises, vemos que o quadro anterior, que anunciava mudanças trazidas pelos Tema Transversal "Orientação sexual", parece sofrer retrocessos, sobretudo, a partir de $2015^{7}$ quando "um discurso anti-sexual e contrário às liberdades conquistadas assola o Brasil de norte a sul" (RIBEIRO; MONTEIRO, 2019, p. 1257). Trata-se do acirramento do novo conservadorismo (LACERDA, 2019), que se coloca contra todas as manifestações culturais, por meio de grupos defensores da moral cristã e dos valores de família por eles idealizados. Ao considerar a fundação do Movimento Escola sem Partido (ESP) ${ }^{8}$, em 2004, e sua maior visibilidade a partir de 2014, pode-se afirmar que, desde então, esses grupos passam a atacar frontalmente a educação sexual escolar, refutando sua pertinência, chegando à judicialização de professores/as e de materiais didáticos ${ }^{9}$. Todas as referências à igualdade de gênero, à diversidade sexual e a temáticas sexuais com ênfase cultural são associadas à esquerda, ao Partido dos Trabalhadores, então no poder, e a ameaças aos direitos dos estudantes cujas famílias partilham de tal entendimento. Organizam-se verdadeiras cruzadas legais (MOURA e SALLES, 2018) contra as práticas curriculares e docentes desenvolvidas em favor de uma educação sexual que integre cultura e biologia. Desse modo, as demandas pela biologização dessas temáticas recebem novo reforço e apesar dos passos dados nessa dianteira, nos quais novas perspectivas de educação sexual surgiram, sofrese um retrocesso. Verifica-se que os aspectos sociais, culturais e ambientais ainda estão interpelados pela persistência de abordagens higienistas e biomédicas que, sob perspectiva iluminista e comportamental, insistem no controle dos corpos.

Como abordado nesta seção, as censuras à educação sexual têm acompanhado governos ditatoriais e, discretamente, nos últimos 30 anos foi beneficiada pelos processos de democratização. Diante de sua inscrição como temas sensíveis, cabe perguntar como as gerações de professores/as dessas disciplinas, em sua trajetória profissional, vêm incorporando

\footnotetext{
${ }^{7}$ Cabe dizer que desde 2004, o governo federal lançou o movimento "Brasil sem homofobia", e em 2011, o MEC produziu um material didático "Escola sem homofobia", que foi vetado pela presidência em virtude de campanha conservadora contrária. Os grupos conservadores acusavam de se tratar de uma propagando que iria incentivar a homossexualidade nos/as estudantes. Posteriormente, tal material - chamado de "kit gay" pelos conservadores foi alvo de fake news na última campanha eleitoral em 2018.

${ }^{8}$ Sobre o movimento Escola sem Partido, consultar Penna (2017).

${ }^{9}$ Disponível em: Pais acionam MP para proibir livro escolar com desenho de pênis em Rondônia. Acesso em: 25 fev. de 2021.
} 
DOI: http://doi.org/10.46667/renbio.v14i1.535

práticas de educação sexual com suas turmas. Como argumentariam sobre as finalidades da educação sexual? Que modos de fazer vêm mobilizando para trabalhar a educação sexual com suas turmas? Que críticas teriam? Que justificativas dariam para a inclusão ou exclusão curricular da educação sexual se estivessem sob o escrutínio dos argumentos neoconservadores? Tais questionamentos orientaram o desenvolvimento da pesquisa que passamos a relatar.

\section{Procedimentos metodológicos}

Neste trabalho, damos prioridade a analisar as relações entre práticas de educação sexual desenvolvidas por professores/as de Ciências e Biologia de diferentes gerações. A opção pelo recorte geracional se justifica não apenas porque se trata de uma temática sensível, mas sobretudo porque sua história é atravessada por contextos sociais que foram provocando mudanças no entendimento do sexo e exercendo pressão seletiva sobre os currículos escolares. Isso porque esses contextos recaem tanto sobre sua dimensão comportamental, dando margem a julgamentos e receituários morais, quanto sobre a abrangência biológica e patológica da educação sexual, abafando, desse modo, as possibilidades de entendê-la fora de modos de controle do corpo.

Daí ponderar que o testemunho geracional pode fertilizar o conhecimento acerca do se ou do como os/as docentes lidam com essa temática ao longo de coortes geracionais. Uma referência importante que também advém do interesse pela categoria geracional diz respeito ao fato de que o ESP sempre se refere a um passado de 30 anos, pois corresponde ao espaço de tempo em que as temáticas curriculares por eles rejeitadas se ampliaram nas escolas, fazendo explícita alusão ao período em que a redemocratização substituiu o regime ditatorial brasileiro. Tal periodização corresponde a gerações de professores/as de Biologia formados entre o final dos anos 1980 e os tempos atuais, os quais assistiram gradativamente a inclusão de temáticas ambientais, de gênero, de raça, de sexualidade na escola como possibilidade inclusiva de alunos e alunas cujas diferenças, por muito tempo, permanecem silenciadas.

Os estudos de Lívia Magalhães (2014) trazem contribuições relevantes para o uso que se pretende fazer da categoria geracional. Articulando memória coletiva e geração - com as contribuições de Karl Mannheim e Maurice Halbwachs -, a autora reconhece a categoria geracional como um recurso heurístico para examinar as funções que os sujeitos exercem na sociedade, pois explicita a pertinência das relações presente-passado em termos de sua diacronia e sincronia para a "definição de políticas, projetos de educação e de sociedade" (MAGALHÃES, 2014, p. 94). De Mannheim, Magalhães mobiliza o próprio conceito de gerações, entendido como "um grupo social delimitado por sua posição de idade ou situação social particular, decorrente de seu pertencimento ao momento histórico determinado" (p. 96). A autora destaca a relação de coexistência entre as gerações e a partilha de interesses e inquietudes comuns e que, considerando uma mesma cronologia, os grupos operam em um "tempo vivencial qualitativo que é diferente um do outro" (MAGALHÃES, 2014, p. 94). Os 
DOI: http://doi.org/10.46667/renbio.v14i1.535

vínculos entre os grupos geracionais não são escolhidos por eles, mas relacionados a uma coexistência na sociedade, ou uma "conexão geracional" conforme define Mannheim.

Portanto, investigar a educação sexual sob o aporte geracional docente pode contribuir para relacioná-la aos contextos sociais, culturais e políticos de seus tempos e favorecer a análise dos modos com que foi trabalhada ao longo de um período de tempo. Nesse intento, o exame da educação sexual pode dar ensejo a conhecer os modos de controle, de regulação e de modulação exercidos sobre a docência (SELLES; ANDRADE, 2016) e maneiras de ressaltar finalidades coerentes com valores democráticos, configurando práticas resistentes às investidas conservadoras. Em outras palavras, enfrentar de dentro da docência as significações culturais que a educação sexual demanda e entender em que medida apontam o esgotamento e a insuficiência de um tratamento biológico, patológico ou meramente moral.

O estudo desenvolvido por Ivor Goodson entre os anos 2004 e 2008 com países da União Europeia (GOODSON, 2019) dialoga com as formulações de Magalhães, quando o autor empregou entrevistas de história de vida que "cobriram um plano de coorte para que diferentes gerações de professores/as tivessem chance de desenvolver suas narrativas de acordo com o período histórico em que haviam trabalhado" (p.74, grifo nosso). As coortes cobertas por Goodson envolveram 3 períodos: docentes que começaram a trabalhar em (i) 1960 e 1970, (ii) 1980 e 1990, e (iii) docentes que começaram a trabalhar recentemente. Definir essas coortes permitiu ao autor entender possibilidades de ação profissional e de narrativas profissionais em pontos particulares dos tempos históricos cobertos por esses coortes no quadro de reformas neoliberais levadas a cabo em seus países (GOODSON, 2019, p. 75). Assim, Goodson estabelece as coortes geracionais tomando como referência o início das carreiras profissionais dos/as docentes participantes. Como se vê, a coorte não é definida necessariamente pelo ano de nascimento dos/as docentes, mas sim com a fixação de um fato comum à vida profissional dos participantes de cada grupo. Considerando que as trajetórias de docentes, por exemplo, podem iniciar sem que se coincida com as faixas etárias de todos eles, a experiência de Goodson, elegendo o período inicial das carreiras docentes serviu de inspiração para esta pesquisa.

Desse modo, a pesquisa empregou o recorte de gerações de professores/as de Ciências e Biologia para entender os processos pelos quais a educação sexual vem sendo trabalhada em escolas em relação aos contextos sociais e profissionais ao longo de 30 anos. Optamos por incluir quatro gerações de professores/as de Ciências e Biologia relacionadas ao momento histórico de sua formação inicial (Quadro 1). Para as entrevistas selecionamos professores/as que tivessem experiência profissional há, pelo menos, cinco anos. Além disso, para apreender uma variedade de gerações escolhemos os/as docentes que tivessem tempos de profissão entre 5, 10, 20 e 30 anos. As entrevistas foram realizadas por meio de programas de reunião on-line, visto que ocorreram durante a pandemia de Covid-19, ao longo do ano de 2020. Todos/as os/as professores/as autorizaram a gravação e o uso das entrevistas para o desenvolvimento desta pesquisa e, para preservar suas identidades, utilizamos nomes fictícios. 
DOI: http://doi.org/10.46667/renbio.v14i1.535

Quadro 1: Informações gerais sobre os/as professores/as entrevistados.

\begin{tabular}{|c|c|c|c|c|c|c|}
\hline Geração & Nome fictício & Idade & Tempo de profissão & Disciplina que leciona & Instituição de formação & Ano de formação \\
\hline I & Clara & 61 & 33 & Biologia/Ciências & UFRRJ & 1986 \\
\hline \multirow{3}{*}{ II } & Carlos & 55 & 28 & Biologia & UERJ & 1992 \\
\cline { 2 - 7 } & Ernesto & 47 & 24 & Biologia & UERJ - FFP & 1997 \\
\hline \multirow{3}{*}{ III } & Rosa & 37 & 10 & Ciências & UERJ - FFP & 2005 \\
\cline { 2 - 8 } & Ana & 37 & 10 & Ciências & UFF & 2005 \\
\hline \multirow{7}{*}{ IV } & Leila & 33 & 5 & Biologia & UERJ-FFP & 2010 \\
\cline { 2 - 8 } & Vladimir & 29 & 6 & Ciências & UFF & 2014 \\
\cline { 2 - 7 } & José & 26 & 5 & Biologia/Ciências & UFRJ & 2015 \\
\hline
\end{tabular}

Fonte: Produzido pelas autoras

Dessa forma, incluímos na Geração I a professora Clara, cuja formação se deu na década de 1980. Esse período foi marcado por intensas transformações relativas ao processo de redemocratização do país, que culminaram na aprovação da Constituição Federal de 1988, após os anos de ditadura militar. Embora tenha sido um momento de amplas discussões sociais, como a própria Clara comenta, seus/as professores/as da universidade, que tiveram formação no regime militar, não incluíam discussões acerca da educação sexual em suas aulas. Somado a isso, outro fator marcante na geração de Clara, em relação às questões de sexualidade, foi a epidemia de AIDS, que no Brasil teve o primeiro caso confirmado em $1982^{10}$. Para César (2009), isto contribuiu para a prevalência de visões biologicistas acerca da sexualidade nas escolas.

Essa mesma condição também atravessou a Geração II, que inclui os professores formados na década de 1990 (Carlos e Ernesto). Com a epidemia de AIDS ainda em alta, a escola tornou-se local privilegiado para o combate e prevenção da doença. Assim, o que se observava era um grande pânico em relação à sexualidade. Além disso, outras questões também marcaram o âmbito educacional da época. Por um lado, havia um significativo processo de desenvolvimento de políticas neoliberais para a educação influenciadas por diretrizes de organizações internacionais: Organizações das Nações Unidas - ONU, Fundo Monetário Internacional - FMI, Banco Mundial - BM, entre outras (PERONI, 2020; BARBOSA, 2020). E, por outro lado, movimentos sociais, LGBTI+ e feministas, principalmente, pressionavam por políticas que atendessem seus direitos sexuais e reprodutivos. É neste contexto que ao final da

${ }^{10}$ Disponível em: http://www.ioc.fiocruz.br/aids20anos/linhadotempo.html Acesso em: em 03 fev 2021. 
DOI: http://doi.org/10.46667/renbio.v14i1.535

década de 1990 são publicados os Parâmetros Curriculares Nacionais, que incluíam como Tema Transversal a Orientação Sexual para o Ensino Fundamental.

Consequentemente, a geração seguinte - Geração III -, que inclui as professoras Rosa e Ana, formada na década de 2000, foi marcada pela vigência dos PCN. Entretanto, alguns autores, sugerem que a falta de discussões no que concerne à educação sexual na formação inicial dos/as professores/as levou a uma baixa adesão da temática por professores/as da escola básica, em especial no formato que prevê o documento (BARROS e COSTA, 2012; VIEIRA e MATSUKURA, 2017). A esse fator, soma-se a criação do movimento Escola Sem Partido (ESP) em 2004, que ainda com pouca expressão nesse período, é resultado de uma crescente onda conservadora que se coloca contrária à inclusão dessa temática nas escolas ${ }^{11}$.

É no contexto da década de 2010 que o ESP atinge maior relevância no âmbito educacional, sendo responsável por diversos Projetos de Lei e de Emendas à Constituição que visavam à proibição das temáticas relacionadas à educação sexual nas escolas, além de incitar a censura de livros didáticos e práticas docentes (FURLANETTO et al, 2018). Nesse cenário, a Geração IV, que inclui os/a professores/a Leila, Vladimir e José, é marcada por fortes disputas em relação à educação sexual, desde suas formações até o início de suas práticas como docentes, em que estão em confronto os movimentos conservadores, que visam a censura à temática, e movimentos progressistas, que insistem na sua importância para promoção de uma educação democrática.

Após a transcrição, leitura e releituras das entrevistas, desenvolvemos as análises das narrativas, buscando encontrar as motivações descritas pelos docentes para entender possíveis mudanças relacionadas a fatores geracionais, com base nas/as quatro coortes geracionais que descrevemos anteriormente. Assim, a partir de um olhar cuidadoso sobre as entrevistas, emergiram três categorias que expressam as fontes de mudanças nas práticas docentes, quais sejam: (i) as questões sociais: remetem às finalidades de socialização próprias da educação que, ao longo dos anos, vão se modificando à medida que as demandas sociais ganham mais visibilidade e se integram ao cotidiano escolar; (ii) as experiências pessoais: exercem um papel significativo nos modos de fazer dos/as professores/as, pois, por meio de suas vivências e histórias de vida os/as docentes vão revisando e modificando seus conhecimentos e práticas; (iii) as demandas dos/as alunos/as: modulam o modo como os/as professores/as selecionam e organizam suas aulas.

${ }^{11} \mathrm{O}$ movimento Escola sem Partido é explicitamente contrário à inclusão da educação sexual nas escolas, conforme o título de uma de suas postagens na página do movimento: Quem disse que educação sexual é obrigatória". Disponível em: https://www.escolasempartido.org/blog/quem-disse-que-educacao-sexual-e-conteudoobrigatorio/ Acesso em: 03 de maio de 2021. 
Para análise dessas narrativas colocamos a proposição de Gert Biesta (2013) sobre finalidades educacionais em diálogo com a perspectiva dos saberes docentes desenvolvida por Maurice Tardif (2014). De Biesta (2013), mobilizamos suas reflexões sobre a função da educação na sociedade. $\mathrm{O}$ autor argumenta que quaisquer propostas educacionais incluem como finalidades, sejam elas explícitas ou implícitas, a qualificação, a socialização e a subjetivação. A primeira está relacionada aos conhecimentos científicos num sentido de informar os/as alunos/as, a segunda se refere aos conhecimentos de cunho social, relacionados à vida em sociedade e aos problemas sociais, e a terceira finalidade diz respeito aos processos de individualização dos sujeitos, ou seja, como estes se enxergam no mundo (BIESTA, 2013). Com base no autor, buscamos entender as narrativas docentes no recorte geracional ao longo de 30 anos, atentas aos modos como trabalharam a educação sexual.

Por sua vez, as contribuições de Tardif (2014) são significativas para associar, em termos geracionais, os modos como os/as docentes foram edificando suas práticas com a educação sexual. Isto porque para o autor os saberes profissionais dos/as professores/as são plurais e heterogêneos porque provêm de diversas fontes. Em seu trabalho, um/a professor/a se serve de sua cultura pessoal, que provém de sua história de vida e de sua cultura escolar anterior; ele também se apoia em certos conhecimentos disciplinares adquiridos na universidade, assim como em certos conhecimentos didáticos e pedagógicos oriundos de sua formação profissional. Ao lado desses, os/as docentes mobilizam e atualizam os conhecimentos curriculares veiculados pelos programas, guias e manuais escolares que empregam no seu cotidiano. Para Tardif, o saber docente se constrói intimamente associado às experiências laborais, produzindo e assentando seus saberes experienciais em tradições peculiares ao ofício de professor. Assim, os saberes experienciais são o "núcleo da cultura docente em ação", forjados no tempo, integrando os demais saberes e são constantemente atualizados ao longo da vida profissional.

Utilizando as proposições de Tardif, entendemos que ao longo da carreira docente, os saberes dos/as professores/as são traduzidos em suas práticas pela combinação de diferentes "modos de fazer", favorecendo a aprendizagem dos estudantes (CARMO; SELLES, 2018). Estes "modos de fazer" mostram a mobilização de saberes da experiência, articulam-se a outros saberes e configuram formas específicas de produção docente. Desse modo, buscamos conhecer alguns modos de fazer em educação sexual dos/as docentes participantes desta pesquisa. 
DOI: http://doi.org/10.46667/renbio.v14i1.535

\section{Fontes de mudanças das práticas de educação sexual}

\subsection{Questões sociais}

Nesta categoria, mobilizamos as contribuições de Biesta (2013), destacando principalmente a função de socialização, uma vez que as questões sociais relacionadas à educação sexual foram priorizadas nas narrativas dos/as professores/as entrevistados/as. Isso sugere que as respostas a essas questões vão ao encontro dessa função proposta pelo autor. Assim, mobilizando essa finalidade educacional, observamos mudanças no interior dos tempos geracionais, não só entre os/as professores/as de diferentes gerações, mas também nos modos de fazer de um/a mesmo/a docente ao longo dos anos. Por exemplo, é possível perceber na fala da professora Clara (Geração I) que no início de sua atuação profissional havia a prevalência de um viés biomédico e informativo, no qual questões como as ISTs e métodos contraceptivos eram prioritariamente discutidas nas suas aulas, justificadas de acordo com a função de qualificação. Entendemos que eleger essa prioridade se relaciona ao contexto histórico da epidemia de AIDS nas décadas de 1980 e 1990 e o número de alunas grávidas. Esse período foi marcado por um reforço das perspectivas higienistas sobre o corpo humano, tendo como foco a prevenção de doenças e da gravidez na adolescência, fatos destacados pela professora:

Eu comecei a fazer seminários, mas com temas mais ligados à atualidade e aí eu comecei com os seguintes temas: o primeiro deles era DST, né, doença sexualmente transmissível; o segundo, métodos contraceptivos; o terceiro, tipos de parto; e o quarto era gravidez na adolescência, porque estava uma explosão de meninas grávidas (Clara - Geração I).

Apesar de ter iniciado sua prática docente com abordagens restritas aos conhecimentos biológicos e com enfoques patológicos, a professora amplia os assuntos a serem trabalhados na sala de aula e investe em um viés cultural e social. Clara comenta que essa mudança na abordagem dos conteúdos sobre educação sexual é influenciada por uma "nova mobilidade social" que tem base nos processos de socialização das novas gerações. Entendemos que essa mudança exibe uma dimensão intergeracional, uma vez que a professora afirma ser uma inclusão bastante recente nas suas práticas. Para Clara, atender exclusivamente à função de qualificação, nos termos propostos por Biesta, não é mais satisfatório:

De uns 5 anos pra cá, uma nova mobilidade social veio trazer mais um assunto, que foi a questão da violência contra os gêneros e os diversos transgêneros. E eu acrescentei [nas minhas aulas] mais um tema: violência sexual, gênero e transgênero. Isso abordando todos os tipos de gênero, que aí [é] uma questão mais da sociologia. Eu não entro na questão mais sociológica da questão dos gêneros, mas levanto [nas aulas], né, o questionamento sobre a questão do feminicídio, né, a questão da mulher, né, como ser social, da homossexualidade, transexualidade, polissexualidade... (Clara - Geração I, grifo nosso). 
DOI: http://doi.org/10.46667/renbio.v14i1.535

De modo semelhante, o professor Ernesto (Geração II) também sentiu a necessidade de atualizar suas aulas levando em consideração as perspectivas sociais e culturais que atravessam a sexualidade humana. Portanto, assim como Clara, Ernesto narra que suas primeiras experiências docentes eram muito focadas nas questões biológicas da sexualidade, destacando os aspectos anatômicos e fisiológicos, mas que, na atualidade, questões como a homossexualidade, por exemplo, "viraram demanda", como ele próprio destaca:

E precisar entender como que o movimento LGBT+ funciona - é que tem um monte de letra, aí às vezes eu me perco na atualização - como que ele funciona, como que as questões queer funcionam, como a questão da afirmação funciona junto com tudo isso, isso pra gente virou uma demanda, porque o colégio ${ }^{12}$ é uma escola muito plural (Ernesto - Geração II, grifo nosso).

Por outro lado, a professora Rosa (Geração III) narra que desde seus primeiros anos como professora sentiu a necessidade de incluir uma abordagem social e cultural sobre a educação sexual, trabalhando perspectivas alternativas sobre os papéis de gênero na paternidade, maternidade e nas relações interpessoais entre homens e mulheres. Isso remete a Guerellus e Martello (2016) quando apontam que, "a escola é um espaço de socialização para a diversidade e para o questionamento da aprendizagem do gênero e da sexualidade”. Assim, observamos que por ser de uma geração mais jovem do que a de Clara e Ernesto, Rosa inclui tais temáticas desde os seus primeiros anos de docência, por serem assuntos que fazem parte de suas vivências e preocupações sociais.

Ah não, então eu vou apresentar o sistema reprodutor de uma forma que a gente vá discutir também sobre a questão do sexo e sobre a relação homem e mulher. Os papéis sociais que esses dois, essas duas figuras, têm na sociedade, quando tem um filho. Nesse momento eu era muito focada pela questão da gravidez na adolescência. Então, é, meio que o meu, a minha intencionalidade era que levasse a uma reflexão dos papéis desiguais entre o homem e a mulher na sociedade e por conta disso, é, tinha que debater sobre isso (Rosa - Geração III).

Só que aí, depois desse meu primeiro momento, nesse meu primeiro ano, eu comecei a enxergar o machismo, o quanto que o machismo implicava nessa questão da gravidez na adolescência, das meninas, né. O quanto que a questão menina não ficar sem ninguém, do namorado que ameaça deixar, o quanto que isso a colocava numa posição vulnerável e por conta disso ela aceitava fazer sexo sem preservativo ou fazer qualquer outra coisa que não se sentisse à vontade (Rosa - Geração III).

As narrativas dos/as docentes, quando examinadas em termos geracionais, mostram que no início de suas carreiras a preocupação com a informação parece ser assumida sem muita criticidade, sobretudo, pelos/as docentes das gerações I e II, o que difere da docente da geração III, que assume a docência já advertida pela justaposição da educação sexual com as questões sociais. Isso não significa que os/as docentes das gerações I e II não eram sensíveis a essas

\footnotetext{
${ }^{12}$ Aqui o professor cita o nome da escola em que trabalha e optamos por omitir essa informação.
} 
DOI: http://doi.org/10.46667/renbio.v14i1.535

questões, mas provavelmente a naturalização da função de qualificação foi sendo desconstruída não apenas pela experiência docente que ia sendo elaborada, mas também porque as pressões sociais desestabilizavam os vieses biomédicos fixados historicamente na educação sexual. Considerando que os/as docentes narram suas experiências no presente, a finalidade de socialização parece colocar a qualificação a seu serviço e mostra que os modos de fazer docente exibem a mescla dessas finalidades, entretanto, sem hierarquizá-las.

\subsection{Experiências Pessoais}

A sexualidade é constituída por múltiplas vivências individuais e coletivas e, desse modo, quando chega à escola, cada pessoa já carrega consigo os valores sexuais que foram apropriados pela e na sua cultura, influenciados pela família e pelo grupo social a que cada estudante faz parte (MAIA \& RIBEIRO, 2011). Obviamente, tais reflexões também incluem os/as docentes, cujas experiências pessoais influenciam como abordarão o assunto na sala de aula. A professora Rosa (geração III), por exemplo, utiliza de sua vivência extraescolar para ampliar os debates sociais acerca do conteúdo de educação sexual.

Os livros didáticos me ajudam a pensar sobre os conteúdos específicos da ciência. Agora, o debate social eu me inspiro e busco na minha vivência enquanto mulher, militante, e aí insiro os conteúdos. (Rosa - Geração III)

Nessa perspectiva, o professor José, pertencente à geração IV, relatou que, apesar de suas experiências e convicções pessoais, teve que introduzir mudanças na abordagem da educação sexual junto a suas turmas, para evitar confrontos com os movimentos conservadores em ascensão, explicitamente marcados na sua geração. Assim, optou por estratégias de ensino para contornar essas armadilhas: tratar o tema, mas evitar ser repreendido, conforme explica:

Então, eu gosto de discutir questões socioculturais. É o meu perfil de professor. Eu não me vejo... eu já me vi uma época... hoje eu não me vejo mais um professor que sempre quer encher o cara de conteúdo para passar no ENEM e vai! Vai embora. Não. Então, é isso que eu te falei. Eu trabalho criando pretexto pras discussões sociais, porque às vezes se eu chegar logo de cara colocando (as questões culturais) poderia gerar algum tipo de problema pra mim. (José - Geração IV)

Em especial, esse relato evidencia que pressões externas à escola exercem influência nos modos de fazer docente em educação sexual, mas parecem ser traduzidas tomando como referência as experiências pessoais ou, em outras palavras, a história de vida dos/as docentes. Tanto o relato da Rosa quanto o do José implicam em considerar, conforme afirma Tardif (2002), que os saberes profissionais dos/as professores/as são temporais e situados, ou seja, são elaborados ao longo do tempo e submetidos aos contextos em que suas práticas acontecem. Como vimos, os/as docentes vão estruturando seus saberes sobre o ensino e sobre seus papéis sociais de maneira enraizada à sua história de vida. Baseados nela solucionam as exigências contextuais e constroem seus modos de fazer docente. A experiência de José indica como ele contorna os constrangimentos externos mesmo nos primeiros anos de prática profissional. Segundo Tardif (2002), esses anos são decisivos na aquisição do sentimento de competência e no estabelecimento das rotinas de trabalho, ou seja, na estruturação da prática profissional. Essa 
DOI: http://doi.org/10.46667/renbio.v14i1.535

estruturação vai se constituindo temporalmente por meio do atravessamento das experiências pessoais dos/as docentes nos contextos de suas práticas: nas decisões que tomam quanto às escolhas dos enfoques para ensinar as temáticas sexuais e nas releituras que fazem dos materiais curriculares. Seus processos identitários vão sendo construídos nessas escolhas e na avaliação dos riscos que podem correr. Em diálogo com o que propõe Biesta (2013), entendemos que as finalidades educacionais também são filtradas por essas experiências pessoais e pelos contextos em que os/as professores/as exercem a docência.

\subsection{Demandas dos/as alunos/as}

No decorrer das entrevistas, observamos que muitos/as professores/as destacaram que a inclusão de temáticas relativas à educação sexual é muito influenciada pelos/as próprios/as alunos/as, que demandam, de diferentes maneiras, informações e discussões a respeito do assunto. Tais demandas, se referem a informações sobre as mudanças próprias da puberdade, às questões sobre os gêneros e a sexualidade, dúvidas sobre as relações sexuais, entre outras, como destacam os/as professores/as de diferentes gerações como Ernesto, Vladimir, Carlos, Clara e Rosa. Essas gerações foram atravessadas por contextos sociais que ora se marcavam pelo pânico em relação às práticas sexuais, resultante da epidemia de HIV, ora por fatores de ordem cultural. Ao longo dessas coortes de gerações, os/as docentes foram produzindo respostas às demandas de seus estudantes, alternando as escolhas pedagógicas para atendê-los.

Essa perspectiva da liberdade de expressão dos alunos de uma maneira geral, né, por ser muito próxima dessa vivência da universidade, diferente do controle mais estrito que existe nas escolas particulares e nas escolas estaduais, o colégio $^{13}$ ele é mais livre, então ele é um ambiente mais propício pra isso. Então essas demandas elas ganham espaço, elas ganham força, tanto assim que a gente tem coletivo feminista no colégio, a gente tem coletivo LGBT+. (Ernesto - Geração II)

A gente está trabalhando isso no oitavo ano, trabalhava antes e continua trabalhando, a recepção dos alunos para esse tema, as curiosidades deles, o interesse deles é enorme, muito grande, são minhas aulas que mais rendem, que os alunos mostram mais interesse e mais vontade, então a recepção deles é ótima. (Vladmir - Geração IV)

Porque uma coisa que não dá para eu fazer agora, em 2020, século XXI, é dizer para eles [estudantes] não transarem, porque eles vão fazer isso mesmo. Então é uma coisa até meio anacrônica eu tentar tirá-los dessa prática, que eles vão fazer mesmo, então é importante eles terem cuidado e fazer da maneira correta e responsável. (Carlos - Geração II)

Nas semanas da alteridade [atividade desenvolvida na escola] quando eles [estudantes] discutem essas questões de sexualidade e de gênero e etc. As salas lotam, lotam. É uma coisa assim muito legal. Então eles sentem-se mais que

\footnotetext{
${ }^{13}$ Como já informamos, optamos por omitir o nome da escola em que o professor trabalha.
} 
DOI: http://doi.org/10.46667/renbio.v14i1.535

contemplados e abraçados com esse tipo de tema. Porque é o que eles estão vivendo, né. (Clara - Geração I)

E aí isso demonstra um pouco essa coisa deles [estudantes] de se interessarem, porque mostra uma carência também de informação, ainda existem um tabu muito grande sobre o tema educação sexual e acho que isso precisa ser tratado como outro conteúdo qualquer, a meu ver, precisa ser naturalizado, infelizmente a gente ainda trata isso como uma coisa proibida. (Rosa Geração III)

Esses relatos evidenciam que, mesmo em gerações distintas, trabalhar a educação sexual significa escutar as demandas dos estudantes. Atender a essas demandas é, portanto, um traço intergeracional que delineia o modo de fazer docente e pode até ir de encontro a valores pessoais. Mesmo quando vinculado a um viés biológico e moralizante, como a constatação do professor Carlos de que será inútil tentar evitar que os/as alunos/as tenham relações sexuais, ou para desconstruir um tabu, como afirma Rosa, são as demandas dos estudantes constitutivas dos seus modos de fazer. Isso tanto moveu o professor Carlos a priorizar a informação, pois entende que ela pode levar a práticas sexuais mais saudáveis (ainda sem definir o que isto significa), quanto incluir a educação sexual como um "conteúdo qualquer", vibrar com a semana da alteridade ou reconhecer que são as demandas dos/as estudantes que ganham força e modulam suas práticas, como relatam, respectivamente, Rosa, Clara e Ernesto.

Recorremos novamente a Tardif quando o autor afirma que os saberes docentes não são apenas temporais e personalizados, eles também são situados, isto é, construídos e utilizados em função de uma situação de trabalho particular, e é em relação a essa situação particular que eles ganham sentido. Tal acepção implica em admitir que os saberes são forjados em uma situação de trabalho à qual os/as docentes devem atender. Isso supõe que os significados atribuídos pelos/as professores/as e pelos/as alunos/as às situações de ensino das temáticas sexuais são elaborados e partilhados dentro dessas próprias situações, como o caso da "semana da alteridade" relatada por Clara. Em diálogo com Biesta (2013), entendemos que, quando os/as docentes respondem às demandas dos/as alunos/as, o caráter situado que marca o saber docente vai ao encontro da função de subjetivação. Desse modo, as narrativas sugerem que os modos de fazer sobre a educação sexual são engendrados pelas demandas dos/as estudantes, são atualizados geracionalmente e estão ancorados nas situações que ajudam a reconhecê-las, mesmo quando os valores morais dos/as docentes são diferentes dos de seus/as estudantes. 


\section{Considerações finais}

Neste texto, problematizamos a educação sexual escolar, revisitando elementos de sua história, para entender seus vínculos com os contextos sociais e como suas abordagens curriculares foram sendo engendradas e modularam as práticas docentes ao longo dos últimos 30 anos. Examinamos essas abordagens em termos de algumas gerações docentes ao longo deste período, apoiadas em autores que destacam a potência do emprego da categoria geracional para entender, de modo articulado, narrativas de vida profissional e os contextos de produção curricular.

Assim sendo, tomamos como pressuposto que os/as docentes produzem currículo e, em particular, delineiam a disciplina escolar, em modalidades inventivas ou modos de fazer (CARMO; SELLES, 2018), que no caso deste trabalho recaem sobre a educação sexual. Registramos que, em diferentes gerações, esses modos de fazer docente foram atualizados por dimensões sociais, influenciados por valores e experiências pessoais e produziram respostas às demandas dos/as estudantes. Dessa maneira, os modos de fazer expressam saberes docentes que concorrem para a produção curricular e são passíveis de serem compartilhados de modo coletivo em coortes geracionais. As categorias foram elaboradas colocando as narrativas de docentes em diálogo com as contribuições dos estudos do currículo, dos saberes docentes e das finalidades educacionais. Isso permitiu entender que as abordagens curriculares de educação sexual integram subjetivamente os saberes experienciais das/os docentes em contextos sociais e pedagógicos submetidos às finalidades educacionais e aos condicionantes temporais.

Ao longo dessas três décadas, conectamos dinamicamente presente e passado de práticas de educação sexual para evidenciar o papel dos/as professores/as na construção curricular, documentando nuances dessas práticas e das experiências vividas ao trabalhar com essa temática com suas turmas. As narrativas docentes remetem a possibilidades de educação sexual que não apenas refratam mecanismos normativos, mas também ajustam as escolhas pedagógicas aos contextos e situações inscritas no seu tempo. Vimos que essas possibilidades não estão restritas às listagens de conteúdos que remetem às referências ao conhecimento biológico. Examinar as narrativas dos/as docentes em suas gerações permitiu conhecer seus modos de negociar o currículo junto a condicionantes externos e internos a seu trabalho, documentando acordos e rejeições que foram atravessados por suas histórias de vida profissional, configurando respostas que rasuraram a hegemonia da informação biológica.

Tais cruzamentos são indícios da impossibilidade de reduzir as abordagens docentes de educação sexual a um fazer obediente a normas e ao prescrito, ou como a contribuição de Biesta (2013) sugere, exclusivamente em atendimento à função de qualificação. Em traçados pedagógicos plurais e singulares para trabalhar a educação sexual, as gerações de docentes desta pesquisa parecem ter integrado a função de qualificação - sem desdenhar do valor do conhecimento - às outras funções da educação escolar para priorizar a formação social de seus/as estudantes, bem como seus processos de subjetivação. Ao examinar suas narrativas, 
DOI: http://doi.org/10.46667/renbio.v14i1.535

entendemos que as finalidades de socialização e subjetivação enquadraram a de qualificação, exibindo modos de fazer docente que as mesclam sem hierarquizá-las.

Por fim, o protagonismo docente na abordagem de educação sexual exibiu marcas geracionais que se atualizaram e enfrentaram os desafios de seus tempos. Desse modo, essas marcas concorrem para a produção de uma memória docente coletiva que registra o esforço desses sujeitos em assumir um compromisso democrático com seus/as estudantes. Tal esforço parece romper com os impositivos biologizantes, higienistas, comportamentais e moralizantes que acompanharam a educação sexual, desde que, racializada, ela foi inserida como um projeto de brasilidade. Ainda que o quantitativo dos/as docentes participantes nesta pesquisa não nos permita generalizar, suas narrativas são indiciárias de possibilidades mais ricas e plenas de trabalhar a educação sexual, sensíveis aos riscos que a população estudantil corre em função da violência sexual, dos preconceitos de gênero e de definições culturais que a exclui socialmente. A reunião dessas práticas em narrativas produz uma memória coletiva docente que pode encorajar resistências a ataques do novo conservadorismo e a desenhar futuros sociais mais promissores para o alunado.

\section{Referências}

AQUINO, Camila; MARTELLI, Andréia Cristina. Escola e educação Sexual: uma relação necessária. SEMINÁRIO DE PESQUISA EM EDUCAÇÃO DA REGIÃO SUL, 9., 2012. Anais do...Caxias do Sul: Unoeste, 2012.

BARBOSA, Maryane Martins. BNCC no estado do Rio de Janeiro: processo de reelaboração da versão nacional. 149f. Dissertação (Mestrado em Educação) - Faculdade de Educação, Universidade Federal Fluminense, Niterói, RJ. 2020.

BARROS, Suzana da Conceição; COSTA, Paula Regina. Educação para a sexualidade : uma questão transversal ou disciplinar no currículo escolar? Revista Electrónica de Enseñanza de las Ciencias, v. 11, n. 1, p. 164-187, 2012.

BIESTA, Gert. Boa educação na era da mensuração. Caderno de pesquisa, v. 42, n.147, p.808-825, 2013.

BRITZMAN, Deborah. Curiosidade, sexualidade e currículo. In: LOURO, G. O corpo educado. 2.ed. Belo Horizonte: Autêntica, 84p. 2000.

CARMO, Edinaldo Medeiros; SELLES, Sandra Escovedo. "Modos de fazer" elaborados por professores de biologia como produção de conhecimento escolar. Revista Brasileira de Pesquisa em Educação em Ciências, v. 18, p. 269-299, 2018.

CÉSAR, Maria Rita de Assis. Gênero, sexualidade e educação: notas para uma "Epistemologia". Educar em Revista, v. 35, p. 37-51, 2009.

COSTA JUNIOR, F.M.; COUTO, M.T. Geração e categorias geracionais nas pesquisas sobre saúde e gênero no Brasil. Saúde Soc. São Paulo, v.24, n.4, p.1299-1315, 2015. 
DOI: http://doi.org/10.46667/renbio.v14i1.535

FELÍCIO, Leandro Alves. Um projeto de Educação sexual para o Brasil: O Círculo Brasileiro de Educação Sexual (1933 -1945). In: SIMPÓSIO NACIONAL DE HISTÓRIA - ANPUH, 26., 2011. Anais do... São Paulo, 2011.

FONTOURA, Antonio José de Albuquerque, o esquecível: método histórico e o pioneirismo na educação sexual no brasil. Rev. HISTEDBR On-line, Campinas, v.18, n.3 [77], p.671697, jul./set. 2018.

FREIRE, Paulo. Pedagogia da esperança. São Paulo: Paz e Terra, 1998.

FURLANETTO, Milene Fontana.; LAUERMANN, Franciele; COSTA, Cristofer Bastista; MARIN, Angela Helena. Educação sexual em escolas brasileiras: revisão sistemática da literatura. Cadernos de Pesquisa, v. 48, n. 168, p. 550-571, 2018.

GIL, Carmem Zeli de Vargas; CAMARGO, Jonas. Ensino de história e temas sensíveis: abordagens teórico-metodológicas. Revista História Hoje, v. 7, n. 13, p. 139-159, 2018.

GOODSON, Ivor. Currículo, narrativa pessoal e futuro social. Campinas: Editora Unicamp, 2019.

GUERELLUS, Jaile Josiane; MARTELLO, Alcemar. A relação da disciplina de Ciências com as questões de gênero e sexualidade: implicações e desafios. Cadernos PDE, (1), 2014.

KOHEN, Micaela.; MEINARDI, Elsa. Problematizando las enseñanzas sobre la menstruación en la escuela: lo disimulado, lo negativo, lo silenciado. Bio-grafía, v.9, p.179-183, 2015.

LACERDA, Marina. O novo conservadorismo brasileiro. São Paulo: Zouk, 2019.

MAGALHÃES, Lívia Diana Rocha. História, memória e geração: remissão inicial a uma discussão político-educacional. Revista HISTEDBR on-line, n.55, p. 94-103, 2014.

MAIA, Ana Claudia Bortolozzi.; RIBEIRO, Paulo Rennes Marçal. Educação Sexual: princípios para ação. Doxa - Revista Paulista de Psicologia e Educação, v.15, v.1, p. 75-84, 2011.

MOREIRA, Antonio Flávio Barbosa; CANDAU, Vera Maria. Currículo, conhecimento e cultura. In: Indagações sobre currículo: currículo, conhecimento e cultura. Brasília: Ministério da Educação, Secretaria de Educação Básica, p. 17-44, 2007.

MOURA, Fernando Pereira; SALLES, Diogo da Costa. Escola Sem Partido e o ódio aos professores que formam crianças (des)viadas. Periodicus, v. 9, n.1, p. 136-160, 2018.

OLIVEIRA, Cristiane. "Libertar o brasileiro de seu captiveiro moral": identidade nacional, educação sexual e família no brasil da década de 1930. Psicologia \& Sociedade; v.24, n.3, p.507-516, 2012.

PENNA, Fernando. O Escola sem Partido como chave de leitura do fenômeno educacional. In: Gaudêncio Frigotto. (Org.). Escola 'Sem' Partido: esfinge que ameaça a educação e a sociedade brasileira. Rio de Janeiro: UERJ, LPP, 2017, v. 1, p. 35-48. 
DOI: http://doi.org/10.46667/renbio.v14i1.535

PERONI, Vera Maria Vidal. Relação público-privado no contexto de neoconservadorismo no brasil. Educação \& Sociedade, v. 41, 2020.

REIS, Toni. Manual de comunicação LGBTI+. Curitiba: Aliança Nacional LGBTI/ GayLatino. 2.ed., 2018. Disponível em: https://www.grupodignidade.org.br/wpontent/uploads/2018/05/manual-comunicacao-LGBTI.pdf Acesso em: 03 de maio de 2021.

RIBEIRO, Paulo Rennes Marçal. A institucionalização dos saberes acerca da sexualidade humana e da educação sexual no Brasil. In: FIGUEIRÓ, Mary Neide Damico. Educação sexual: múltiplos temas, compromissos comuns. Londrina: Universidade Estadual de Londrina. p. 129-140. 2009.

RIBEIRO, Paulo Rennes Marçal; MONTEIRO, Solange Aparecida de Souza. Avanços e retrocessos da educação sexual no Brasil: apontamentos a partir da eleição presidencial de 2018. RIAEE - Revista Ibero-Americana de Estudos em Educação, Araraquara, v. 14, n. esp. 2, p. 1254-1264, jul. 2019.

SELLES, Sandra Escovedo.; ANDRADE, Everardo Paiva. Políticas curriculares e subalternização do trabalho docente. Educação em Foco (UFJF), v. 21, n. 1, p. 39-64, 2016.

SIMONNEAUX, Jean; SIMONNEAUX, Laurence. Educational configurations for teaching environmental socioscientific issues within the perspective of sustainability research. Science Education, v. 42, n. 1, p. 75-94, 2012.

TARDIF, Maurice. Saberes docentes e formação profissional. 17. ed. Petrópolis: Vozes, 2014.

TEIXEIRA, Pedro; OLIVEIRA, Roberto Dalmo Varallo Lima; QUEIRÓZ, Glória Regina Campello. Conteúdos Cordiais - Biologia humanizada para uma escola sem mordaça. São Paulo: Ed. da Física, 2019.

VIEIRA, Priscila Mugnai.; MATSUKURA, Thelma Simões. Modelos de educação sexual na escola: concepções e práticas de professores do ensino fundamental da rede pública. Revista Brasileira de Educação, v. 22, n. 69, p. 453-474, 2017.

Recebido em março de 2021. Aprovado em maio de 2021.

Revisão gramatical realizada por: Síntia de Albuquerque Novais E-mail: sintia.pacto.em@gmail.com 